\title{
Maximal values of sniff nasal inspiratory pressure in healthy subjects
}

\author{
Christophe Uldry, Jean-William Fitting
}

\begin{abstract}
Background - Inspiratory muscle strength is often better reflected by oesophageal pressure during a maximal sniff (sniff POES) than by maximal inspiratory pressure (PImax). Sniff PoEs can be estimated non-invasively by measuring the sniff nasal inspiratory pressure (SNIP). The aim was to establish maximal normal values for the SNIP and to compare them with PImax.

Methods - One hundred and sixty healthy subjects (80 men) aged 20-80 years were recruited. All subjects had a forced vital capacity (FVC) of $\mathbf{> 8 0} \%$, a forced expiratory volume in one second $\left(F E V_{1}\right) / F V C$ of $>85 \%$ predicted value, and a body mass index of $18-31 \mathrm{~kg} / \mathrm{m}^{2}$. Because PImax is known to be reduced in the supine posture, the SNIP was measured in both the sitting and the supine positions. PImax sustained over one second was measured from functional residual capacity (FRC) in the sitting position with a standard flanged mouthpiece during four manoeuvres. SNIP was measured from FRC in the sitting and supine positions using a catheter through a plug occluding one nostril during 10 maximal sniffs through the contralateral nostril. For each test the largest pressure measured in $\mathrm{cm} \mathrm{H}_{2} \mathrm{O}$ was taken into account.
\end{abstract}

Results - For both men and women maximal SNIP was negatively correlated with age, and was similar in the sitting and the supine positions. In the sitting position maximal SNIP was greater or equal to PImax in 107 of 160 subjects. The mean (SD) ratio SNIP/PImax was $1.08(0.22)$ in men and $1.17(0 \cdot 29)$ in women.

Conclusions - Normal values of maximal SNIP can be predicted from age and sex. Maximal SNIP is similar in the sitting and the supine position and is significantly higher than PImax in healthy subjects. The low level of agreement between maximal SNIP and PImax indicates that the two manoeuvres are not interchangeable but complementary.

(Thorax 1995;50:371-375)

Keywords: respiratory pressures, respiratory muscles.

The assessment of inspiratory and expiratory muscle strength classically relies on the pressures measured at the mouth during a maximal inspiratory or expiratory effort performed against an occlusion (PImax and PEmax). ${ }^{1}$
However, because the manoeuvres are closely dependent on the subject's collaboration - that is, coordination and volitional contraction the results are prone to considerable variability. Thus, low values can reflect either a true muscle weakness or a lack of motivation and coordination. An alternative method consists of using short, maximal sniffs. Inspiratory muscle strength is often better reflected by oesophageal pressure during a maximal sniff (sniff POES) than by PImax. ${ }^{2}$ However, the sniff PoEs has limited clinical usefulness because it requires an oesophageal balloon catheter system. Slightly less invasive positions of the balloon have been described, including the nasopharynx or the mouth. ${ }^{3}$ Finally, sniff PoEs can be estimated entirely non-invasively by the sniff nasal inspiratory pressure (SNIP) measured through a plug occluding one nostril during a sniff performed through the contralateral nostril. ${ }^{4}$ The present study was performed with several aims related to maximal SNIP: (1) to establish normal values in adults, (2) to test the influence of body posture, (3) to determine the appropriate number of trials, and (4) to compare maximal SNIP with PImax.

\section{Methods}

SUBJECTS

We recruited 160 healthy white volunteers ( 80 men) aged $20-80$ years, who were divided into four age groups, each group consisting of 20 men and 20 women: group $120-35$ years, group 2 36-50 years, group 3 51-65 years, and group $466-80$ years. None of them was involved in regular physical training for competition, and only a few were accustomed to performing the manoeuvres. None of them had asthma, rhinitis, previous nasal surgery or neuromuscular disease. All had a forced vital capacity (FVC) of $>80 \%$ and forced expiratory volume in one second $\left(\mathrm{FEV}_{1}\right) / \mathrm{FVC}$ of $>85 \%$ of predicted value. All had a body mass index of $18-31 \mathrm{~kg} / \mathrm{m}^{2}$, with $25 \%$ of both men and women having a body mass index higher than $25 \mathrm{~kg} / \mathrm{m}^{2}$. The physical characteristics of the subjects are shown in table 1 . The study was approved by the ethics committee of our hospital and all subjects gave their informed consent.

MEASUREMENTS

$\mathrm{FEV}_{1}$ and FVC were measured by mass flow sensor (SensorMedics 6200 Autobox, Yorba Linda, California, USA). The SNIP was measured through a plug occluding one nostril dur- 
Table 1 Median (range) physical characteristics of 160 healthy subjects

\begin{tabular}{llllll}
\hline & Sex & Sample size & Age (years) & Weight $(\mathrm{kg})$ & Height $(\mathrm{cm})$ \\
\hline Group 1 & $\mathrm{M}$ & 20 & $26 \cdot 0(21-35)$ & $70 \cdot 5(61-100)$ & $184(172-193)$ \\
20-35 years & $\mathrm{F}$ & 20 & $23 \cdot 0(20-33)$ & $54 \cdot 5(49-70)$ & $168(158-178)$ \\
Group 2 & $\mathrm{M}$ & 20 & $39 \cdot 0(36-50)$ & $72 \cdot 0(58-95)$ & $174(160-183)$ \\
36-50 years & $\mathrm{F}$ & 20 & $41 \cdot 0(36-49)$ & $62 \cdot 5(46-76)$ & $166(151-178)$ \\
Group 3 & $\mathrm{M}$ & 20 & $59 \cdot 5(52-64)$ & $82 \cdot 0(59-95)$ & $173(163-188)$ \\
51-65 years & $\mathrm{F}$ & 20 & $57 \cdot 0(51-65)$ & $65 \cdot 5(53-83)$ & $164(156-178)$ \\
Group 4 & $\mathrm{M}$ & 20 & $70 \cdot 5(67-80)$ & $72(60-102)$ & $171(163-190)$ \\
66-80 years & $\mathrm{F}$ & 20 & $72 \cdot 0(66-80)$ & $61 \cdot 5(48-86)$ & $163(156-178)$ \\
\hline
\end{tabular}

ing a sniff performed through the contralateral nostril. The plug was made of waxed ear plugs (Calmor, Switzerland) hand fastened around the tip of a polyethylene catheter (length $100 \mathrm{~cm}$, internal diameter $1 \mathrm{~mm}$ ). The catheter was connected to a pressure transducer (Micro Switch $126 \mathrm{PC}$, linearity $0-350 \mathrm{~cm} \mathrm{H}_{2} \mathrm{O}$, Honeywell, Freeport, Illinois, USA) and the pressure was recorded on paper (Gould EasyGraph, Valley View, Ohio, USA). The subjects were studied in the sitting position without prior training. They were asked to breathe normally with closed mouth and to perform 10 maximal, short, and sharp sniffs from FRC, each separated by 30 seconds. FRC was not controlled but was identified as the end of expiration during quiet breathing. No visual feedback was provided. Subsequently, the SNIP was measured during 10 maximal sniffs performed in the supine position. All manoeuvres were recorded and the highest pressure was taken into account. If the maximal value was obtained with the tenth sniff in either posture, additional manoeuvres were recorded until the maximal pressure dropped. Criteria used to select the suitable sniffs for analysis were: (1) a pressure tracing showing a regular upstroke and sharp peak; (2) a total sniff duration of less than 0.5 second.

PImax was measured using a standard flanged mouthpiece connected to the same pressure transducer via a polyethylene catheter (length $100 \mathrm{~cm}$, internal diameter $1 \mathrm{~mm}$ ). A $1 \mathrm{~mm}$ leak was opened to avoid participation of orofacial muscles. The subjects were studied in the sitting position, breathing through the nose with the mouth occluded by the mouthpiece. They were asked to occlude their nose and to perform four maximal inspiratory efforts from FRC, each separated by one minute. The inspiratory effort had to be sustained and the maximal recorded pressure maintained during one second was taken into account. PImax was then measured from RV according to the same technique. Similarly, PEmax was measured dur- ing four maximal expiratory efforts both from TLC and from FRC, each separated by one minute. If the maximal pressure was obtained with the fourth manoeuvre for either measurement, additional manoeuvres were required until the maximal pressure dropped. The transducer was calibrated before each measurement session using a $\mathrm{U}$ tube water manometer.

\section{DATA ANALYSIS}

SNIP, PImax, and Pemax designate the amplitudes of pressure change from atmospheric pressure and are expressed in absolute values. Unless otherwise stated, the values are means and standard deviations (SD). Maximal values of SNIP in the sitting position (SNIPsit), SNIP in the supine position (SNIPsup), and PImax from FRC were compared by ANOVA for repeated measures followed by the paired $t$ test with Bonferroni's correction. Linear regression was calculated between SNIPsit and age separately for men and women. The agreement between SNIPsit and PImax from FRC, as well as between SNIPsit and SNIPsup, was assessed by the method of differences against the means according to Bland and Altman. ${ }^{5}$ Each trial of SNIPsit and SNIPsup performed by every subject was numbered from 1 to 10 according to the order of achievement. The mean of each of the 10 trials was assessed for the whole group in the sitting and supine positions. Using a paired $t$ test with Hochberg correction for multiple comparisons ${ }^{6}$ the mean of each from the first to the ninth trial was then compared with the mean of the tenth trial.

\section{Results}

The data for inspiratory and expiratory muscle strength of men and women according to age groups are shown in table 2. Maximal SNIP was correlated with age but not with height or body mass index. For both men and women the relationship between SNIPsit and age was

Table 2 Mean (SD) values of maximal sniff nasal inspiratory pressure in sitting (SNIPsit) and supine (SNIPsup) positions, of maximal inspiratory pressure (PImax) in the sitting position from functional residual capacity (FRC) and residual volume (RV), and of maximal expiratory pressure (PEmax) from FRC and total lung capacity (TLC) in 160 healthy subjects

\begin{tabular}{|c|c|c|c|c|c|c|c|}
\hline $\begin{array}{l}\text { Age groups } \\
\text { (years) }\end{array}$ & $n$ & $\begin{array}{l}\text { SNIPsit } \\
\left(\mathrm{cm} \mathrm{H} \mathrm{H}_{2} \mathrm{O}\right)\end{array}$ & $\begin{array}{l}\text { SNIPsup } \\
\left(\mathrm{cm} \mathrm{H} \mathrm{H}_{2} \mathrm{O}\right)\end{array}$ & $\begin{array}{l}\text { PImax FRC } \\
\left(\mathrm{cm} \mathrm{H} \mathrm{H}_{2} \mathrm{O}\right)\end{array}$ & $\begin{array}{l}\operatorname{PImax} R V \\
\left(\mathrm{~cm} \mathrm{H}_{2} \mathrm{O}\right)\end{array}$ & $\begin{array}{l}\text { PEmax FRC } \\
\left(\mathrm{cm} \mathrm{H} \mathrm{H}_{2} \mathrm{O}\right)\end{array}$ & $\begin{array}{l}\text { PEmax } T L C \\
\left(\mathrm{~cm} \mathrm{H} \mathrm{H}_{2} \mathrm{O}\right)\end{array}$ \\
\hline $\begin{array}{l}\text { Men: } \\
20-35 \\
36-50 \\
51-65 \\
66-80\end{array}$ & $\begin{array}{l}20 \\
20 \\
20 \\
20\end{array}$ & $\begin{array}{r}117.0(29.5) \\
105.0(24.5) \\
111.5(15.5) \\
91.0(21.5)\end{array}$ & $\begin{array}{r}112.5(23.0) \\
108.0(20.0) \\
111.5(17.5) \\
91.5(21.5)\end{array}$ & $\begin{array}{r}109.5(27.0) \\
105.0(20.5) \\
103.5(21.5) \\
82.5(22.5)\end{array}$ & $\begin{array}{r}117.0(25.0) \\
113.5(20.5) \\
114.0(26.5) \\
90.0(25.0)\end{array}$ & $\begin{array}{l}127 \cdot 5(32 \cdot 0) \\
131 \cdot 5(34 \cdot 0) \\
129 \cdot 0(22 \cdot 0)^{*} \\
102 \cdot 5(32 \cdot 0)\end{array}$ & $\begin{array}{l}145 \cdot 0(38 \cdot 0) \\
146 \cdot 5(34 \cdot 0) \\
148 \cdot 0(40 \cdot 0)^{*} \\
118 \cdot 0(39 \cdot 0)\end{array}$ \\
\hline $\begin{array}{l}\text { Women } \\
20-35 \\
36-50 \\
51-65 \\
66-80\end{array}$ & $\begin{array}{l}20 \\
20 \\
20 \\
20\end{array}$ & $\begin{array}{l}84.0(14.5) \\
94.0(21.0) \\
83.5(18.0) \\
75.5(11.0)\end{array}$ & $\begin{array}{l}87 \cdot 0(15 \cdot 5) \\
92 \cdot 5(18 \cdot 0) \\
86 \cdot 0(18 \cdot 5) \\
78 \cdot 5(11 \cdot 0)\end{array}$ & $\begin{array}{l}77.5(18.0) \\
86.5(21.0) \\
79.5(17.0) \\
58.0(16.0)\end{array}$ & $\begin{array}{l}79 \cdot 5(19 \cdot 5) \\
88 \cdot 0(18 \cdot 0) \\
85 \cdot 5(21 \cdot 0) \\
67 \cdot 5(17 \cdot 0)\end{array}$ & $\begin{array}{l}84 \cdot 0(15 \cdot 5) \\
94 \cdot 5(24 \cdot 5) \\
80 \cdot 5(15 \cdot 5) \\
69 \cdot 0(18 \cdot 0)\end{array}$ & $\begin{array}{r}100 \cdot 0(23.0) \\
114.0(37.0) \\
90.0(15.5) \\
79.0(21.0)\end{array}$ \\
\hline
\end{tabular}

${ }^{*} \mathrm{n}=19$ because Pemax could not be measured in one subject because of a technical problem. 

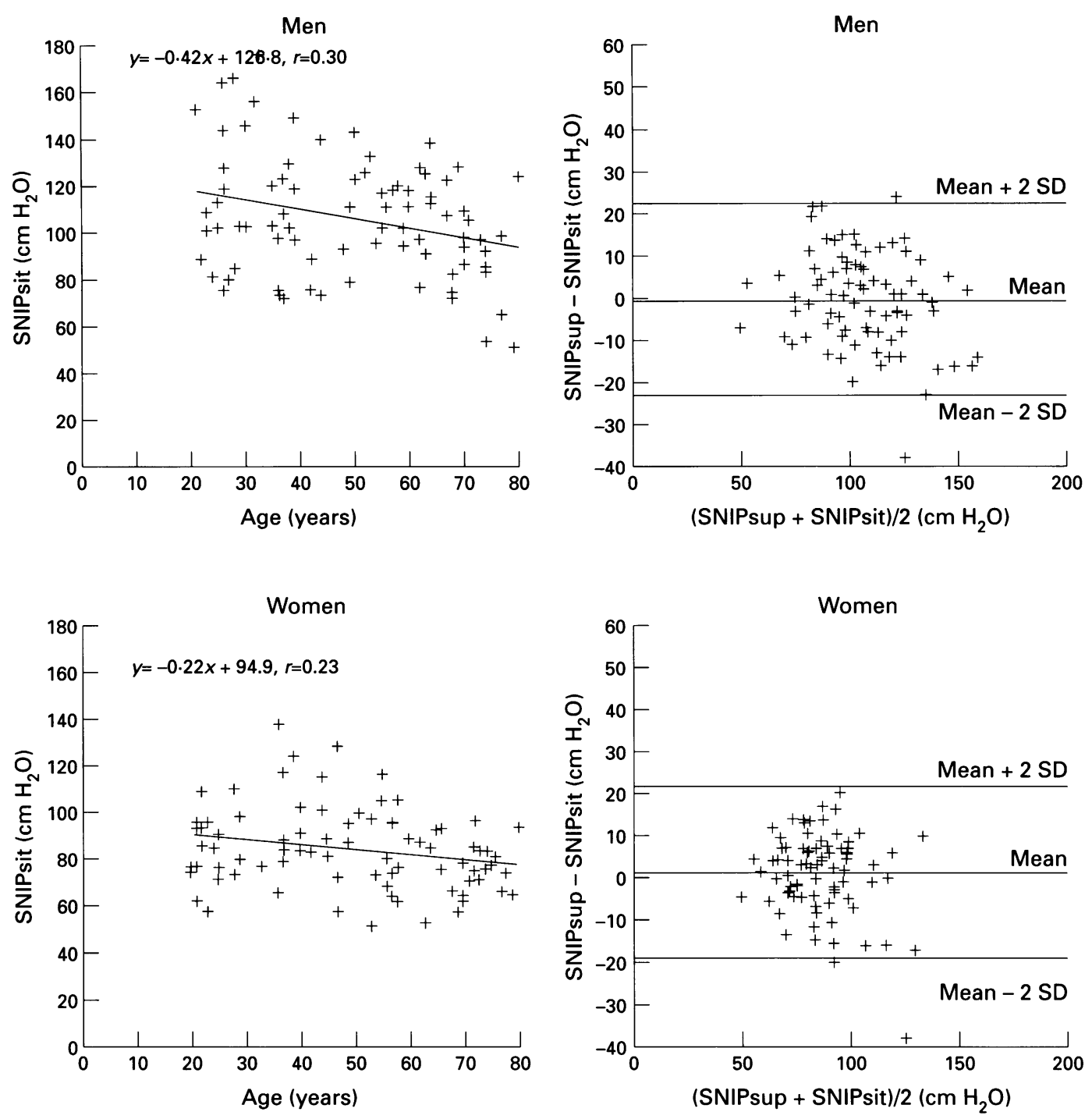

Figure 1 Plot of maximal sniff nasal inspiratory pressure in the sitting position (SNIPsit) versus age in 80 men and 80 women.

described by a linear regression (fig 1). For men the prediction equation is: SNIP (cm $\left.\mathrm{H}_{2} \mathrm{O}\right)=-0.42$ age $+126 \cdot 8$; residual standard deviation $=23 \cdot 8$. For women the prediction equation is: $\mathrm{SNIP}\left(\mathrm{cm} \mathrm{H}_{2} \mathrm{O}\right)=-0 \cdot 22$ age + 94.9; residual standard deviation $=17 \cdot 1$. Substracting 1.64 residual standard deviation from the predicted value will provide the lower limit above which lie $95 \%$ of healthy subjects.

The maximal values of SNIP were similar in the sitting and in the supine positions $(p=N S)$. Considering the maximal value of each subject, fig 2 presents a plot of the difference between SNIPsup and SNIPsit against their mean, respectively, in men and women. In men the ratio SNIPsup/SNIPsit was $1 \cdot 01(0 \cdot 11)$ and the mean difference (d) was $-0.20(11.55) \mathrm{cm}$ $\mathrm{H}_{2} \mathrm{O}$. The limits of agreement were for the upper limit $22.90 \mathrm{~cm} \mathrm{H}_{2} \mathrm{O}$ and for the lower limit $-23.30 \mathrm{~cm} \mathrm{H}_{2} \mathrm{O}$. In women the ratio SNIPsup/SNIPsit was $1.03(0.13)$ and the mean difference (d) was $1.89(9.97) \mathrm{cm} \mathrm{H}_{2} \mathrm{O}$. The limits of agreement for the upper limit were $21.83 \mathrm{~cm} \mathrm{H}_{2} \mathrm{O}$ and for the lower limit $-18.05 \mathrm{~cm} \mathrm{H}_{2} \mathrm{O}$.

The mean of the 10 values of SNIPsit and 10 SNIPsup is shown in fig 3 . In the sitting

Figure 2 Difference between maximal sniff nasal inspiratory pressure in the sitting (SNIPsit) and supine (SNIPsup) positions against the mean of these two variables in 80 men and 80 women.

position the tenth value was significantly greater than each from the first to the seventh trial $(p<0.05)$, but was similar to the eighth and ninth values. There was no significant difference between the tenth trial and each from the first to the ninth trial in the supine position.

In the sitting position from FRC, values of SNIP were greater or equal to those of PImax in 107 of 160 subjects ( 50 men and 57 women). SNIPsit and SNIPsup were both greater than PImax $(p<0 \cdot 005)$. Considering the maximal value of each subject, fig 4 presents a plot of the difference between SNIPsit and PImax against their mean, respectively, in men and women. In men the ratio SNIPsit/PImax was $1.08(0.22)$ and the mean difference $(d)$ was $5.85(17.95) \mathrm{cm} \mathrm{H}_{2} \mathrm{O}$. The limits of agreement for the upper limit were $41.75 \mathrm{~cm} \mathrm{H}_{2} \mathrm{O}$ and for the lower limit $-30.05 \mathrm{~cm} \mathrm{H}_{2} \mathrm{O}$. The agreement between SNIPsit and PImax in women was assessed according to the same method. The ratio SNIPsit/PImax was $1 \cdot 17(0 \cdot 29)$ and the mean difference (d) was $8 \cdot 74(16 \cdot 13) \mathrm{cm}$ $\mathrm{H}_{2} \mathrm{O}$. The limits of agreement for the upper limit were $41.00 \mathrm{~cm} \mathrm{H}_{2} \mathrm{O}$ and for the lower limit $-23.52 \mathrm{~cm} \mathrm{H}_{2} \mathrm{O}$. 

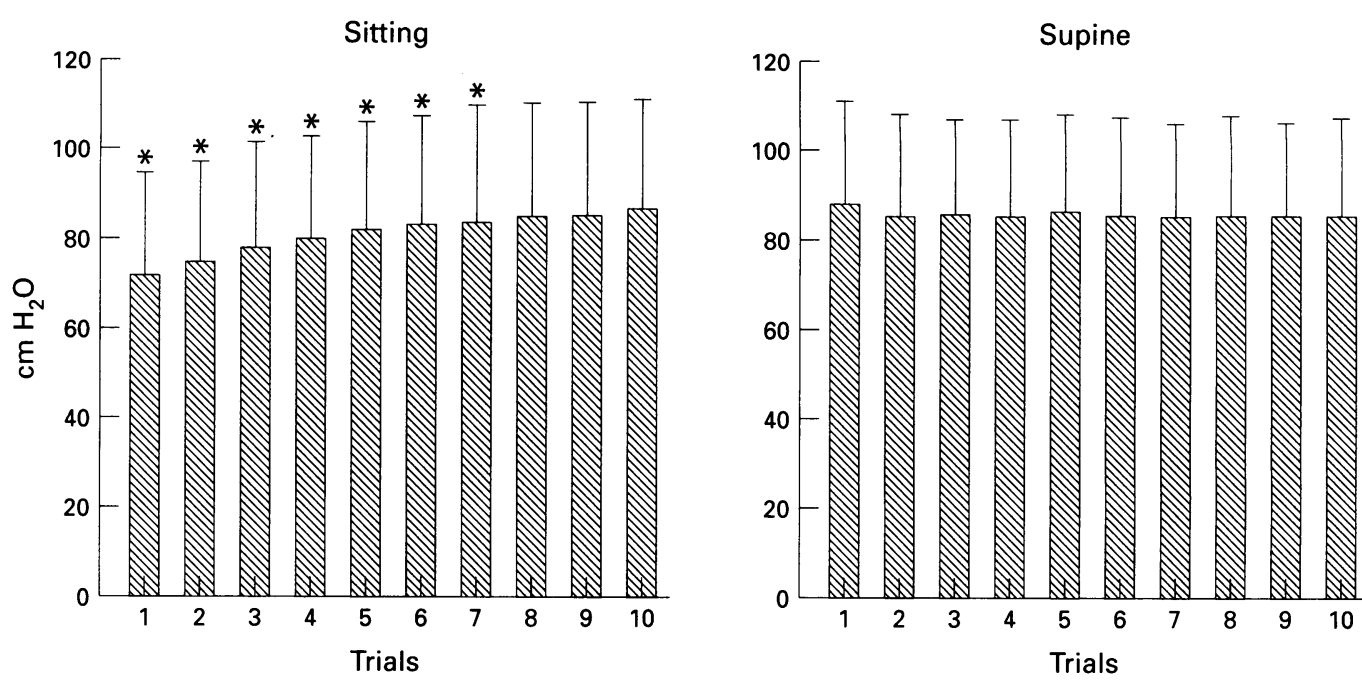

Figure 3 Mean (SD) values of each trial of sniff nasal inspiratory pressure in the sitting and supine positions. The measurements were always performed first in the sitting position. In each position each trial was compared with the 10th trial. ${ }^{*} p<0 \cdot 05$
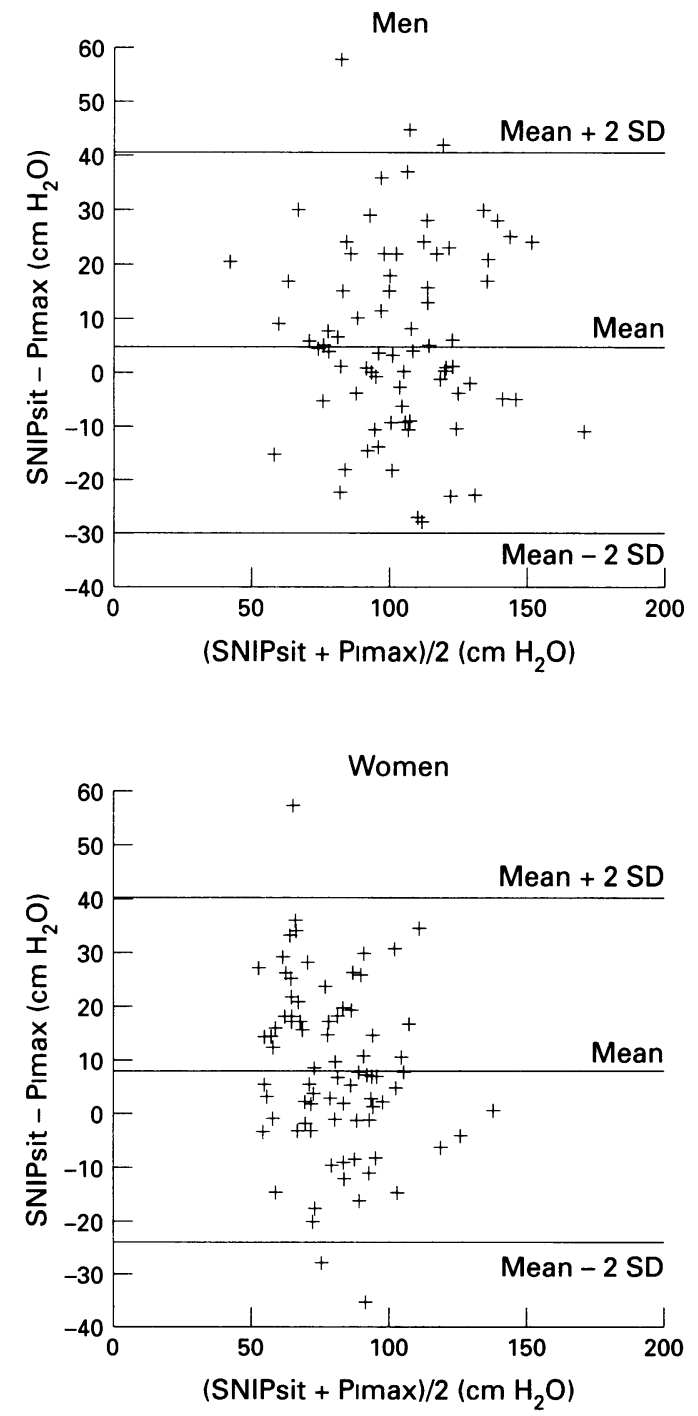

Figure 4 Difference between maximal sniff nasal inspiratory pressure in the sitting position (SNIPsit) and maximal inspiratory pressure (PImax) in the sitting position from FRC against the mean of these two variables in 80 men and 80 women.

\section{Discussion}

Several studies have underlined the importance of the sniff manoeuvre as a reliable and practical test of inspiratory muscle strength. Thus, Laroche $e t a l^{2}$ showed the value of sniff PoEs, compared with PImax, in the assessment of global inspiratory muscle strength. With certain limitations, sniff POES can be estimated from nasopharyngeal or mouth pressure. ${ }^{37}$ Recently, Héritier et $a l^{4}$ showed that the SNIP - that is, the nasal pressure measured through a plug occluding one nostril during a maximal sniff performed through the contralateral nostril provides a reliable and non-invasive estimation of PoEs both in healthy volunteers and in patients with neuromuscular or skeletal disorders.

The similarity between upper and lower airway pressures during a dynamic manoeuvre is explained by the phenomenon of nasal collapse. The airflow through the nose is regulated by a resistance located in the nostrils. ${ }^{89}$ The nasal flow limiting segment, or nasal valve, is situated in the first $2.5 \mathrm{~cm}$ from the external orifice. ${ }^{9}$ During the sniff, when a critical transnasal

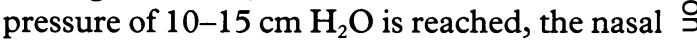
valve collapses. ${ }^{89}$ Beyond the point of collapse $\frac{D}{O}$ there is only a small pressure gradient between extrathoracic and intrathoracic airways. It $\mathcal{N}$ should be noted that this holds true only in $N$ the absence of airways obstruction or of lung N fibrosis which prevent accurate transmission of pleural pressure to the upper airways. ${ }^{10}$

Being reliable, simple, and non-invasive, the $\frac{\mathscr{C}}{\mathbb{D}}$ SNIP appears to be potentially useful for the ? clinical assessment of inspiratory muscle $T$ strength. In the present study we established normal values for the SNIP in adults. We found that they were negatively correlated with age, and that they were independent of height and 0 body mass index. Thus, SNIP can be predicted for either sex from a first degree equation including age.

In this group of 160 healthy subjects maximal values of SNIP were similar in the sitting and in the supine positions. This is at variance with a previous study which used a different technique and showed that mouth sniff pressure was lower in the supine position. ${ }^{11}$ Because our measurements were always performed first 
in the sitting position, it may be argued that the supine values were increased by a continuing learning effect. Indeed, a learning effect was observed, but was completed within the first seven manoeuvres in the sitting position. A continuing learning effect was ruled out by the absence of further increment of SNIP during the last three maneouvres in the sitting position, as well as by its complete stability during the 10 supine manoeuvres.

We chose to record 10 manoeuvres for measuring maximal SNIP. The results show that the number is probably appropriate, as the maximal value was obtained after seven trials. Ten manoeuvres is not too many because the values of maximal SNIP did not decline during 20 consecutive manoeuvres - that is, 10 in the sitting followed by 10 in the supine position. Moreover, a few subjects performed up to 30 trials without a fall in the maximal values. Thus, we observed no manifestation of fatigue after 20-30 maximal sniffs, contrary to the hypothesis of a previous study. ${ }^{11}$ It is not surprising that the tension time index was far below the fatigue threshold $(0 \cdot 15-0 \cdot 18$ for the diaphragm), considering contraction times of less than 500 milliseconds and pauses of 30 seconds between sniffs.

SNIP and PImax were measured from FRC rather than from RV because inspiratory muscle strength is overestimated at levels below FRC due to the elastic recoil pressure of the thorax. ${ }^{1213}$ We found that SNIP was greater than PImax in the sitting position. According to the force-velocity relationship the converse might have been expected. Indeed, the sniff is a dynamic manoeuvre with some increase in the lung volume and some distortion in the chest wall, whereas PImax is considered as quasistatic. Three factors may explain why the SNIP is often greater than PImax. Firstly, dynamic changes in human diaphragm length were described during maximal inspiratory effort against occlusion using sequential radiography, underlining that this manoeuvre does not represent an isometric contraction either. ${ }^{14}$ Secondly, the level of recruitment of inspiratory muscle groups is different during a sniff and during a PImax manoeuvre. The electromyographic activity of the diaphragm is greater during a maximal sniff than during a PImax effort, whereas the activity of the intercostal and sternomastoid muscles is similar during the two manoeuvres. ${ }^{15}$ Thirdly, the sniff measurement is easier and less unpleasant than the PImax manoeuvre and may thereby allow maximal muscular recruitment to be achieved more often.

The comparison of SNIP and PImax by the method of differences against the means according to Bland and Altman ${ }^{5}$ is meaningful. The limits of agreement between SNIP and PImax are wide, illustrating that these two manoeuvres are not interchangeable but rather complement one another in the assessment of inspiratory muscle strength. PImax and Pemax are the most physiological methods for measuring respiratory muscle strength. In the case of normal values no further test is necessary. However, in the presence of low PImax values the SNIP offers a way to differentiate between true inspiratory muscle weakness and difficulty in performing the sustained effort against an occluded airway.

From this study in healthy subjects we conclude that maximal SNIP can be predicted from age by a first degree equation for both sexes, is similar in the sitting and supine positions, can be obtained with 10 manoeuvres, is significantly greater than PImax in subjects unaccustomed to performing the manoeuvres, and complements rather than replaces PImax.

The authors thank Antigone Askitoglu for her technical assistance and Dr François Feihl for statistical advice. This study was supported by a grant from the Société Suisse de Pneumologie.

1 Black LF, Hyatt RE. Maximal respiratory pressures: norma values and relationship to age and sex. Am Rev Respir Dis 1969;99:696-702.

2 Laroche CM, Mier AK, Moxham J, Green M. The value of sniff oesophageal pressures in the assessment of global inspiratory muscle strength. Am Rev Respir Dis 1988;138: 598-603.

3 Koulouris N, Mulvey DA, Laroche CM, Sawicka EH, Green M, Moxham J. The measurement of inspiratory muscle strength by sniff esophageal, nasopharyngeal, and mouth pressures. Am Rev Respir Dis 1989;139:641-6.

4 Héritier F, Rahm F, Pasche P, Fitting JW. Sniff nasal inspiratory pressure: a noninvasive assessment of inspiratory muscle strength. Am f Respir Crit Care Med 1994; 150:1678-83.

5 Bland JM, Altman DG. Statistical methods for assessing agreement between two methods of clinical measurement. Lancet 1986;i:307-10.

6 Hochberg Y, Benjamini Y. More powerful procedures for multiple significance testing. Statistics in Medicine 1990;9: 811-8

7 Héritier F, Perret C, Fitting JW. Esophageal and mouth pressure during sniffs with and without nasal occlusion. Respir Physiol 1991;86:305-13.

8 Bridger GP, Proctor DF. Maximal nasal inspiratory flow and nasal resistance. Ann Otol Rhinol Laryngol 1970;79: 481-8.

9 Haight JSJ, Cole P. The site and function of the nasal valve. Laryngoscope 1983;93:49-55.

10 Mulvey DA, Elliott MW, Koulouris NG, Carroll MP, Moxham J, Green M. Sniff oesophageal and nasopharyngeal pressures and maximal relaxation rates in patients with respiratory dysfunction. Am Rev Respir Dis 1991;143 950-3.

11 Heijdra YF, Dekhuijzen PNR, van Herwaarden CLA, Folgering HTM. Differences between sniff mouth pressures and static maximal inspiratory mouth pressures. Eur Respir $\mathcal{f} 1993 ; 6: 541-6$.

12 Agostini E, Rahn H. Abdominal and thoracic pressures at different lung volumes. 7 Appl Physiol 1960;15:1087-92.

13 Rahn H, Otis AB, Chadwick LE, Fenn WO. The pressure volume diagram of the thorax and lung. Am f Physiol 1946;146:161-78.

14 Gandevia SC, Gorman RB, McKenzie DK, Southon FCG. Dynamic changes in human diaphragm length: maximal inspiratory and expulsive efforts studied with sequential radiography. $\mathcal{f}$ Physiol 1992;457:167-76.

15 Nava S, Ambrosino N, Crotti P, Fracchia C, Rampulla C. Recruitment of some respiratory muscles during three maximal inspiratory manoeuvres. Thorax 1993;48:702-7. 